\title{
Respuesta humoral anti proteína E7 del virus del papiloma tipo 16 definida mediante el uso de péptidos sintéticos y proteína recombinante
}

\author{
María Mercedes Bravo; Alba Lucía Cómbita; Martha Mesa; \\ Amanda Varela; Oscar Orozco*; Gilberto Martínez**
}

\begin{abstract}
RESUMEN: 249 sueros de pacientes con diagnóstico de Carcinoma Cervical (CA INV), Neoplasia Intraepitelial Cervical (NIC) y de mujeres sanas fueron analizados mediante la técnica de ELISA empleando 14 icosapéptidos sintéticos sobrelapados que representan la secuencia de aminoácidos de la proteína E7 del virus del papiloma tipo 16 (E7-VPH16). Las principales regiones de la proteína reconocidas por las pacientes con diagnóstico de CA. invasivo fueron las representadas por los péptidos E7 (1-20) (11.3\%) y E7 (66-85) (12.5\%). Ninguno de los controles mostró reactividad hacia estos péptidos. Para confirmar esta reactividad, los sueros fueron analizados mediante inmunotransferencia con proteína E7-VPH16 recombinante; $28.2 \%$ de los sueros del grupo de CA invasivo fueron positivos, ningún suero del grupo control reconoció la proteína recombinante. Las reactividades de sueros de pacientes y controles hacia péptidos diferentes de E7 (11-30) y E7 (66-85) no fueron confirmadas. La detección de anticuerpos hacia estos dos péptidos podría ser útil en el seguimiento de las pacientes con CA de cérvix.
\end{abstract}

PALABRAS CLAVES: Carcinoma cervical, papilomavirus, anticuerpos.

SUMMARY: 80 sera from patients with invasive cervical carcinoma (INV CA), 92 from patients with cervical intraepithelial neoplasia (CIN), and 77 from healthy women were analyzed for IgG antibodies to Human Papillomavirus type 16 early protein E7 (HPV16-E7) by ELISA using 14 overlapping icosapeptides covering the entire sequence of the protein. The main regions of the HPV16-E7 protein recognized by the INV CA patients were those represented by peptides E7(1-20) $(11.3 \%)$, and E7(66-85) $(12.5 \%)$. None of the control serum samples presented reactivity against the peptides. To confirm these reactivities, sera were analyzed by immunoblot against the HPV16-E7 recombinant protein: $\mathbf{2 8 . 2 \%}$ of sera from the INV CA group and none from the control group were positive. Tests with the recombinant protein confirmed the reactivities to synthetic peptides E7(1-20) and E7(66-85) in the INV CA group. More interestingly, all the controls were negative with the recombinant protein, suggesting that their reactivities with internal peptides were unspecific. These results indicate that antibodies to $\mathrm{E} 7(1-20)$ and $\mathrm{E} 7(66-85)$ could be conveniently used as markers for the disease.

KEY WORDS: Cervical carcinoma, papilomavirus, antibodies.

\section{Introducción}

El genoma de los virus de papiloma humano (VPH) ha sido detectado en la mayoría de carcinomas cervicales. De los más de 70 tipos caracterizados, los tipos virales 16 y 18 son los que se asocian con mayor frecuencia con carcinoma de cérvix y lesiones preinvasivas (NIC 1, 2, 3) (Pfister et al., 1987; Dürst et al., 1983; Galloway et al., 1989).

La exposición a un virus generalmente induce anticuerpos específicos en el suero del huésped, existen métodos de detección de infección basados en la medición de anticuerpos circulantes en un número importante de afecciones virales, además el estudio de esta respuesta inmune permite hacer una mejor definición de la interacción biológica virus-huésped. En el modelo de los $\mathrm{VPH}$, uno de los blancos de esta respuesta inmune a

* Sección de Inmunología.

** Sección de Ginecología. estudiar es la oncoproteína viral E7, postulada como uno de los factores clave en la tumorigénesis viral. Su presencia y expresión están muy relacionadas con el desarrollo del carcinoma cervical (Dyson et al., 1989; Phelps et al., 1988; Seedorf et al., 1987).

Existen varios métodos para detectar infecciones virales basados en la medición de niveles de anticuerpos específicos. Con los VPH la limitante ha sido la fuente de antígeno, debido a la dificultad para propagar in vitro el virus y a la poca cantidad de viriones en las lesiones. Como alternativas se han empleado como antígenos péptidos sintéticos y proteínas recombinantes. Por ejemplo, se han empleado péptidos sintéticos sobrelapados probados con sueros de pacientes con enfermedades asociadas a VPH16 y de grupos control (Krchnack et al., 1990; Dillner et al., 1990). En estos y otros estudios empleando proteínas recombinantes (revisado en Dillner, 1994a y Tindle \& Frazer, 1994), se han encontrado con mayor frecuencia anticuerpos hacia la oncoproteína viral 
E7-VPH16 en pacientes con carcinoma cervical que en controles apareados por edad. Sinembargo, es aún necesario conocer más acerca de la clase de epítopes que son reconocidas por estos pacientes y también definir cual es la correlación entre las reactividades anti-péptido sintético y anti proteína recombinante.

Con el propósito de ubicar las epítopes reconocidas por los pacientes con carcinoma cervical, neoplasia intraepitelial cervical y los controles sanos, en esta comunicación se reporta el uso de 14 péptidos sintéticos sobrepuestos derivados de E7 de VPH16 en la detección de anticuerpos anti proteína E7 en cada grupo. Para confirmar que la reactividad observada era realmente inducida por la proteína E7, estos sueros también se analizaron con una proteína recombinante GST/E7VPH16.

\section{Materiales y métodos}

\section{Sueros}

Se obtuvieron muestras de pacientes que asistían por primera vez a la consulta de Ginecología del Instituto Nacional de Cancerología, Bogotá, Colombia. Se incluyeron pacientes con diagnóstico de carcinoma cervical y neoplasia intraepitelial cervical. Como controles normales, se obtuvieron sueros de mujeres que asistieron a examen citológico en la Liga de Lucha contra el Cáncer, Seccional Bogotá, cuyo resultado fue normal.

\section{Péptidos sintéticos}

Se utilizaron 13 péptidos sintéticos de veinte aminoácidos y uno de 23 aminoácidos, sobrelapados en diez aminoácidos cubriendo la totalidad de la secuencia de las proteínas E7 de VPH 16. Los péptidos fueron sintetizados en el Instituto de Inmunología del Hospital San Juan de Dios utilizando el método de síntesis múltiple en fase sólida, descrito por Houghten (1985). La pureza de los péptidos obtenidos fue analizada por HPLC en fase reversa en una columna C18. La secuencia de aminoácidos y localización de cada péptido se muestra en la tabla 1 .

\section{ELISA}

Los péptidos fueron acoplados en placas de 96 pozos (NUNC IMMUNOPLATE II). Se colocaron $2 \mathrm{mg}$ de péptido diluido en tampón Carbonato-Bicarbonato 10 $\mathrm{mM}, \mathrm{pH} 9,6$, por pozo y se incubó toda la noche a $4^{\circ} \mathrm{C}$. Posteriormente, se colocaron $200 \mathrm{ml}$ de solución de gelatina al $0.2 \%$ en PBS, una hora a $37^{\circ} \mathrm{C}$. Luego de tres lavados con PBS-Tween $0.05 \%$, los sueros fueron probados en dilución $1 / 20$, se colocaron $100 \mathrm{ml}$ de cada suero en duplicado y se incubó por una hora, luego se lavaron las placas y se colocó el conjugado anti IgG humanaperoxidasa (SIGMA) y se incubó una hora. Luego de cinco lavados la reacción fue revelada mediante la adición de $100 \mathrm{ml}$ de ABTS [2,2' -Azino-di (3-etilbenztiazolinasulfonato)] (SIGMA) disuelto en tampón citrato-fosfato, $0.003 \%$ de peróxido de hidrógeno, luego de una hora se determinó la absorbancia a $405 \mathrm{~nm}$. Para cada suero, se restó el promedio de reactividad en pozos sin péptido del promedio de reactividad de pozos con
Tabla 1.

PEPTIDOS SINTETICOS E7 DE VPH16

\begin{tabular}{|crl|}
\hline PEPTIDO & REGION & \multicolumn{1}{c|}{ SECUENCIA } \\
\hline p 844 & $1-20$ & MHGDTPLHEYMLDLQPETT \\
p 671 & $6-25$ & PTLHEYMLDLQPETTDLYCY \\
p 673 & $16-35$ & QPETTDLYCYEQLNDSSEDEE \\
p 675 & $26-45$ & EQLNDSSEEEDEIDGPAGDA \\
p 676 & $31-50$ & SSEEEDEIDGPAGQAEPDRA \\
p 677 & $36-55$ & DEIDGPGQAEPDRAHYNIV \\
p 678 & $41-60$ & PAGQAEPDRAHYNIVTFCCK \\
P 845 & $46-65$ & EPDRAHYNIVTFCCKCDSTL \\
P 846 & $51-70$ & HYNIVTFCCKCDSTLRLCVQ \\
P 888 & $56-75$ & TFCCKCDSTLRLCVQSTHVD \\
P 889 & $61-80$ & CDSTLRLCVQSTHVDIRTLE \\
P 890 & $66-85$ & RLCVQSTHVDIRTLEDLLMG \\
P 891 & $71-90$ & STHVDIRTLEDLLMGTLGIV \\
P 892 & $76-98$ & IRTLEDLLMGTLGIVCPICSQLP \\
\hline
\end{tabular}

péptido para calcular la reactividad neta. A cada suero se le asignó un valor de positivo o negativo para cada péptido, usando un punto de corte basado en la distribución de los valores de absorbancia del grupo control excluyendo los valores por encima del promedio más tres desviaciones estándar. Los promedios y desviaciones estándar de los valores de absorbancia para cada péptido fueron calculadas para el grupo control, los sueros con valor mayor al promedio más tres desviaciones estándar fueron excluidos. Los promedios y desviaciones estándar fueron recalculados y se excluyeron sueros adicionales si era necesario, utilizando el mismo criterio. Este procedimiento se repitió hasta que ningún valor de absorbancia superaba el promedio, más tres desviaciones estándar y el promedio final más tres desviaciones estándar se tomó como punto de corte.

\section{Construcción del vector de expresión pGEX5T/E7- VPH16}

Se emplearon las metodologías de clonaje ya establecidas (Sambrook et al., 1989) para construir el plásmido pGEX5T/E7-VPH16.

El ADN de VPH16 fue digerido en los sitios NsiI-PstI para obtener el gen E7 (nt 562-858). El fragmento E7 fue religado en fase usando el kit de ligación de ADN de PROMEGA (Berthold, 1992).

Bacterias E. coli, cepa JM101, fueron transformadas con el plásmido recombinante; las colonias resistentes a ampicilina fueron estudiadas por hibridización in situ en filtro, y análisis de restricción para confirmar la presencia y orientación adecuada del gen E7.

\section{Preparación de la proteína de fusión GST-E7}

Bacterias JM101 transformadas con el plásmido pGEX5T/E7-VPH16 fueron cultivadas a $37^{\circ} \mathrm{C}$, diluidas 
$1 / 10$ con medio LB e incubadas 1.5 horas más, para luego hacer la inducción con IPTG $0.5 \mathrm{mM}$ durante 4 horas. Para la purificación de la proteína recombinante GST-E7, $10 \mathrm{ml}$ de cultivo fueron centrifugados y el sedimento resuspendido en PBS con lisozima $0.1 \mathrm{mg} / \mathrm{ml}$, luego de 20 minutos a $0^{\circ} \mathrm{C}$, las bacterias fueron sonicadas $(5 \times 10 \mathrm{seg}$. a $\left.0^{\circ} \mathrm{C}\right)$, el homogenizado celular fue separado por centrifugación a $8000 \mathrm{~g}$ por $10 \mathrm{~min}$. La fracción insoluble (cuerpos de inclusión) fue solubilizada en Sarcosyl al $1.5 \%$, TRIS $50 \mathrm{mM}$, EDTA $1 \mathrm{mM}$ pH 8.0. La proteína GST-E7 fue purificada por electroforesis preparativa en gel de poliacrilamida (SDS-PAGE) al $12.5 \%$. La banda de gel con la proteína E7 fue cortada y macerada y la proteína electroeluida. Finalmente, la proteína GST-E7 fue hidrolizada con trombina. $50 \mathrm{mg}$ de la proteína de fusión, en un volumen de $500 \mathrm{ml}$ de PBS, fueron mezclados con $4 \mathrm{ml}$ de una solución de trombina de $300 \mathrm{U} / \mathrm{ml}$ y $5 \mathrm{ml}$ de $\mathrm{CaCl}$. Se incubó durante 1 hora con agitación suave.

\section{Inmunotransferencia}

$15 \mathrm{mg}$ de proteína GST-E7 hidrolizada con trombina fueron sometidos a SDS-PAGE en un gel al 15\%. Las proteínas fueron transferidas a un filtro de Nitrocelulosa (BIORAD) a $0.8 \mathrm{~mA} / \mathrm{cm}^{2}$ usando un aparato de transferencia semiseca. El filtro fue sumergido en leche descremada al $5 \%$ en $\mathrm{PBS}$ por 1 hora a $\mathrm{T}^{\circ}$ ambiente, luego se incubó 12 horas a $4^{\circ} \mathrm{C}$ con los sueros diluidos 1:20 en PBS-leche. Como control positivo se colocó suero de ratón anti GST-E7 diluido 1:200. Luego de 5 lavados de 5 minutos cada uno, el filtro se colocó durante 1 hora en una solución de conjugado anti IgG humana o murinaperoxidasa. Los complejos de anticuerpo fueron visualizados con aminoetilcarbazol.

\section{Immunodot}

$4 \mathrm{ml}$ de una solución de GST-E7 purificada $(50 \mathrm{mg} /$ $\mathrm{ml}$ ) fueron colocadas sobre una tira de nitrocelulosa, posteriormente este filtro se trató de la manera descrita para la inmunotransferencia.

\section{Métodos estadísticos}

Las proporciones de sueros positivos en los diferentes grupos fueron comparadas usando la prueba de Chicuadrado o la prueba exacta de Fisher cuando fue necesario. Un valor $\mathrm{P}$ por debajo de 0.025 fue considerado significativo. El coeficiente kappa fue empleado para medir la concordancia en la reactividad de los sueros hacia algunos péptidos, o entre péptidos y proteína recombinante.

\section{Resultados}

Se obtuvieron muestras de suero de 249 mujeres que fueron clasificadas según su diagnóstico en tres grupos: $\mathrm{El}$ grupo CA INV (Carcinoma invasivo) $(\mathrm{n}=80$; rango de edad 21 a 71 años, media 47), el grupo NIC (NIC 1, 2, 3) $(n=92$; rango de edad 22 a 78 años, media 40$)$, y el grupo control, mujeres con citología normal $(n=77$; rango de edad 19 a 64 años, media 39). Los 249 sueros fueron probados en ELISA sobre los 14 péptidos.

Los porcentajes de sueros en los tres grupos con anticuerpos hacia cada uno de los péptidos se muestran en la tabla 2. Se encontraron diferencias significativas en la prevalencia de anticuerpos entre el grupo de CA invasivo y el grupo control para el péptido E7-VPH16 (1-20) $\mathrm{p}<0.0031$ y para el péptido E7-VPH16 (66-85) p<0.0015. Cuando se consideró la reactividad hacia estos dos péptidos, la diferencia entre el grupo CA INV y el grupo control fue más pronunciada $(16.25 \%$ vs $0 \%, \mathrm{p}<0.0004)$. Las comparaciones entre los grupos NIC y control no mostraron diferencias significativas en reactividad hacia los péptidos.

Se observó una correlación moderada en la reactividad hacia los péptidos E7 (1-20) y E7 (66-85). Seis sueros del grupo CA INV mostraron reactividad simultánea hacia E7 (1-20) y E7 (66-85), mientras que siete sueros reaccionaron con uno u otro. Un coeficiente kappa de 0.58 mostró que la concordancia observada con estos péptidos excedía aquella esperable solamente por el azar.

Un $26 \%$ de sueros en el grupo de CA invasivo, $13 \%$ de NIC y $10.4 \%$ de controles reconocieron al menos un péptido de E7-VPH16. (CA INV v.s Control $\mathrm{p}<0.019$, NIC v.s. control $p<0.77)$. La reactividad en el grupo control estaba dirigida hacia varios péptidos, pero ningún suero reaccionó con E7 (1-20) ó E7 (66-85).

Con el propósito de obtener una confirmación de la reactividad de los sueros con los péptidos de E7 en ELISA, 64 muestras de suero del grupo CA INV, 75 del grupo NIC y 45 del grupo control, todas seleccionadas al azar, fueron probadas por inmunotransferencia e inmunodot con la proteína recombinante GST-E7/VPH16 digerida con trombina. Como se muestra en la tabla 3 , se encontraron diferencias importantes en reactividad del grupo CA INV versus los grupos NIC y control: $28.2 \%$ de sueros del grupo CA INV, $1.3 \%$ del grupo NIC y ninguno del grupo control reconocieron la proteína E7 por inmunotransferencia (CA INV v.s Control $p<0.003$ ). Por inmunodot, $23.4 \%$ de los sueros del grupo CA INV, 5.3\% de NIC fueron positivos, ningún suero del grupo control reaccionó con la proteína E7 (CA INV v.s. Control $\mathrm{p}<0.0001)$. En las figuras $1 \mathrm{~A}$ y $1 \mathrm{~B}$ se ilustran las reactividades observadas en inmunotransferencia $\mathrm{e}$ inmunodot respectivamente.

Se hizo una comparación de las reactividades hacia péptidos sintéticos y proteína recombinante. En la tabla 4 se muestra la comparación de las reactividades observadas en el grupo de CA invasivo: de 18 sueros del grupo CA INV que reaccionaron con la proteína recombinante por inmunodot, 13 reconocieron péptidos sintéticos en ELISA. Todos estos suerơs reconocieron los péptidos E7 (1-20) y/o E7 (66-85); la reactividad hacia otros péptidos fue diversa y escasa. La concordancia en la reactividad hacia la proteína recombinante $\mathrm{E} 7 \mathrm{y}$ la reactividad hacia los péptidos E7 (1-20) y/o E7 (66-85) fue sustancial (coeficiente kappa $=0.70$ ).

La positividad en ELISA de 8 sueros del grupo CA INV no fue confirmada por inmunotransferencia. Siete de esos sueros reconocieron péptidos diferentes de 
Tabla 2

ANTICUERPOS ANTI PEPTIDOS SINTETICOS DERIVADOS DE E7 DE VPH 16 EN SUEROS DE LOS GRUPOS CA INV, NIC Y CONTROL

\begin{tabular}{|c|c|c|c|c|}
\hline \multirow[b]{2}{*}{ PEPTIDO } & \multirow[b]{2}{*}{$\begin{array}{c}\text { ELISA } \\
\text { PUNTO DE } \\
\text { CORTE }\end{array}$} & \multicolumn{3}{|c|}{ No. de sueros positivos $(\%)$} \\
\hline & & $\begin{array}{c}\text { NORMAL } \\
\mathrm{n}=77\end{array}$ & $\begin{array}{c}\text { NIC } \\
\mathrm{n}=92\end{array}$ & $\begin{array}{c}\text { CA INV } \\
\mathrm{n}=80\end{array}$ \\
\hline $1-20$ & 0.106 & $0(0.0)$ & $2(2.2)$ & $9(11.3)^{*}$ \\
\hline $6-25$ & 0.173 & $2(2.6)$ & $1(1.1)$ & $2(2.5)$ \\
\hline $16-35$ & 0.305 & $2(2.6)$ & $1(1.1)$ & $2(2.5)$ \\
\hline $26-45$ & 0.175 & $2(2.6)$ & $0(0.0)$ & $1(1.3)$ \\
\hline $31-50$ & 0.253 & $0(0.0)$ & $2(2.2)$ & $0(0.0)$ \\
\hline $36-55$ & 0.096 & $0(0.0)$ & $2(2.2)$ & $2(2.5)$ \\
\hline $41-60$ & 0.165 & $2(2.6)$ & $0(0.0)$ & $1(1.3)$ \\
\hline $46-65$ & 0.180 & $1(1.3)$ & $0(0.0)$ & $0(0.0)$ \\
\hline $51-70$ & 0.087 & $1(1.3)$ & $0(0.0)$ & $0(0.0)$ \\
\hline $56-75$ & 0.113 & $1(1.3)$ & $0(0.0)$ & $2(2.5)$ \\
\hline $61-80$ & 0.173 & $0(0.0)$ & $0(0.0)$ & $1(1.3)$ \\
\hline $66-85$ & 0.150 & $0(0.0)$ & $4(4.3)$ & $10(12.5)^{*}$ \\
\hline $71-90$ & 0.204 & $1(1.3)$ & $0(0.0)$ & $0(0.0)$ \\
\hline $76-98$ & 0.157 & $0(0.0)$ & $(6.5)$ & $4(5.0)$ \\
\hline \multicolumn{5}{|l|}{ E7/16 (1-20) o } \\
\hline E7/16 (66-85) & & $0(0.0)$ & $6(6.5)$ & $13(16.25)^{*}$ \\
\hline Cualquier E7-16 & & $8(10.4)$ & $12(13.0)$ & $21(26.2)$ \\
\hline
\end{tabular}

Tabla 3

ANTICUERPOS ANTI PROTEINA RECOMBINADO GST-E7/VPH 16 EN SUEROS DE LOS GRUPOS CA INV, NIC Y CONTROL

\begin{tabular}{|lllc|}
\hline & \multicolumn{4}{c|}{ No. de sueros positivos (\%) } \\
\cline { 2 - 4 } & $\begin{array}{c}\text { NORMAL } \\
\mathrm{n}=45\end{array}$ & $\mathrm{n}=74$ & $\mathrm{n}=64$ \\
\hline Inmunotransferencia & $0(0.0)$ & $1(1.3)$ & $18(28.2)$ \\
Inmunodot & $0(0.0)$ & $4(5.3)$ & $15(23.4)$ \\
& & & \\
\hline
\end{tabular}

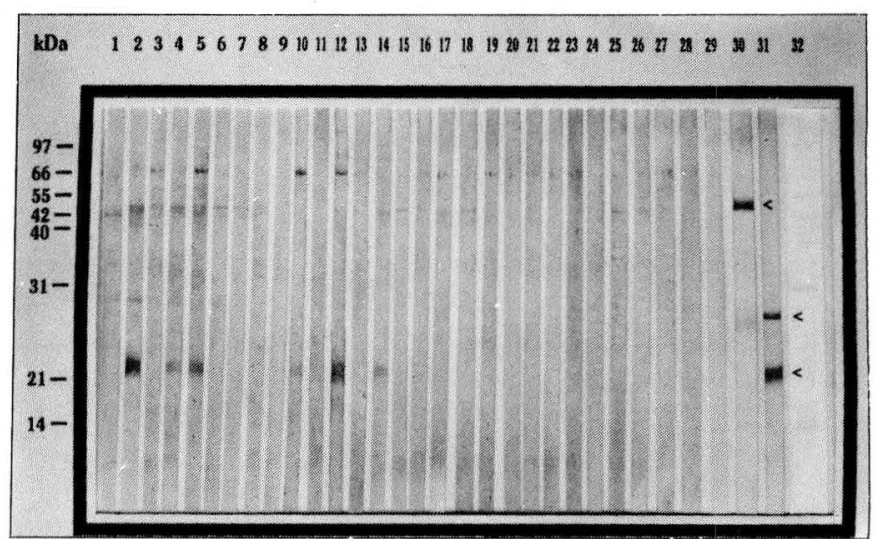

Figura 1. A.

Resultados de inmunotransferencia de algunos sueros. El producto E7 mostró un peso molecular de $21 \mathrm{kd}$ y fue reconocido por el suero de ratón anti GST-E7, línea 31 (GST-E7 digerida con trombina); en la línea 30 se muestra la reactividad del antisuero con la proteína GST-E7; las líneas 2, 4, 5, 10, 12 y 14 muestran sueros positivos para anticuerpos anti E7; las líneas 1, 3, 6-9, 11, 13, 15-29, muestran sueros negativos. 


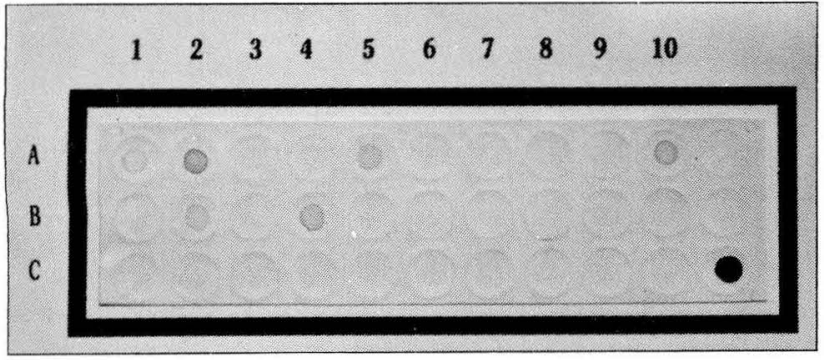

Figura 1. B.

Resultados de inmunodot. La posición c11 muestra la reactividad del antisuero de ratón anti GST-E7, las posiciones a1, a2, a5, a10, b2, b4 muestran sueros positivos.
E7 (1-20) y E7 (66-85); solamente uno reconoció E7 (1-20) con una D.O cercana al punto de corte.

En la tabla 5 se muestra la comparación de las reactividades observadas al grupo NIC: 4 sueros de grupo NIC que fueron positivos en inmunodot, y uno en inmunotransferencia no reconocieron ningún péptido sintético. Por el contrario, la reactividad de 12 sueros del grupo NIC hacia los péptidos sintéticos, 4 de éstos hacia E7 (66-85), no fue confirmada por inmunotransferencia. Del grupo normal, 8 sueros que mostraron reactividades hacia péptidos diferentes de E7 (1-20) ó E7 (66-85), no reconocieron la proteína E7 recombinante (ver tabla 6).

Tabla 4

COMPARACION DE LAS REACTIVIDADES EN ELISA, INMUNOTRANSFERENCIA E INMUNODOT EN EL GRUPO CA INV.

\begin{tabular}{|c|c|c|c|c|c|c|c|c|c|c|c|c|c|c|c|c|}
\hline \multirow[t]{2}{*}{ SUERO } & \multirow[t]{2}{*}{ I.T. } & \multirow[t]{2}{*}{ I.D. } & \multicolumn{14}{|c|}{ ELISA } \\
\hline & & & $1-20$ & $6-25$ & $16-35$ & $26-45$ & $31-50$ & $36-55$ & $41-60$ & $46-55$ & $51-76$ & $56-76$ & $61-80$ & $66-85$ & $71-90$ & $76-98$ \\
\hline 1 & + & + & 0.489 & - & - & - & - & 0.384 & - & - & - & - & - & 1.745 & - & - \\
\hline 10 & + & + & - & - & - & - & - & - & - & - & - & - & - & 0.290 & - & 0.262 \\
\hline 11 & + & + & 0.280 & 0.307 & - & - & - & 0.495 & 1.150 & - & - & - & - & 0.779 & - & 0.346 \\
\hline 23 & + & - & 0.153 & 0.204 & 0.274 & 0.240 & - & - & - & - & - & - & - & - & - & - \\
\hline 39 & + & + & 0.358 & - & - & - & - & - & - & - & - & - & - & - & - & - \\
\hline 44 & + & + & 0.451 & - & - & - & - & - & - & - & - & - & - & 0.203 & - & - \\
\hline 68 & + & + & 0.565 & - & - & - & - & - & - & - & - & - & - & 0.608 & - & - \\
\hline 90 & + & + & - & - & - & - & - & - & - & - & - & - & & 0.736 & - & 0.252 \\
\hline 92 & + & + & - & - & - & - & - & - & - & - & - & 0.267 & - & - & - & - \\
\hline 1061 & + & - & - & - & - & - & - & - & - & - & - & - & - & 0.675 & - & - \\
\hline 1072 & + & + & - & - & - & - & - & - & - & - & - & - & - & 0.454 & - & - \\
\hline 1126 & + & + & 0.225 & - & - & - & - & - & - & - & - & - & - & 1.596 & - & - \\
\hline 1180 & + & + & 0.279 & - & - & - & - & - & - & - & - & - & - & 0.399 & - & - \\
\hline 41 & + & - & - & - & - & - & - & - & - & - & - & - & - & - & - & - \\
\hline 101 & + & + & - & - & - & - & - & - & - & - & - & - & - & - & - & - \\
\hline 120 & + & + & - & - & - & - & - & - & - & - & - & - & - & - & - & - \\
\hline 1040 & + & - & - & - & - & - & - & - & - & - & - & - & - & - & - & - \\
\hline 1050 & + & + & - & - & - & - & - & - & - & - & - & - & - & - & - & - \\
\hline 18 & - & - & 0.119 & - & 0.326 & - & - & - & - & - & - & - & - & - & - & - \\
\hline 22 & - & - & - & - & - & - & - & - & - & - & - & - & 0.206 & - & - & - \\
\hline 89 & - & - & - & - & - & - & - & - & - & - & - & - & - & - & - & 0.252 \\
\hline 91 & - & - & - & - & - & - & - & - & - & - & - & 0.159 & - & - & - & - \\
\hline 1113 & - & - & - & - & - & - & - & - & - & - & - & - & - & - & - & 0.171 \\
\hline 1148 & - & - & 0.392 & - & - & - & - & - & - & - & - & - & - & - & - & - \\
\hline
\end{tabular}


Tabla 5

COMPARACION DE LAS REACTIVIDADES EN ELISA, INMUNOTRANSFERENCIA E INMUNODOT EN EL GRUPO NIC.

\begin{tabular}{|c|c|c|c|c|c|c|c|c|c|c|c|c|c|c|c|c|}
\hline \multirow[t]{2}{*}{ SUERO } & \multirow[t]{2}{*}{ I.T. } & \multirow[t]{2}{*}{ I.D. } & \multicolumn{14}{|c|}{ ELISA } \\
\hline & & & $1-20$ & $6-25$ & $16-35$ & $26-45$ & $31-50$ & $36-55$ & $41-60$ & $46-55$ & $51-76$ & $56-76$ & $61-80$ & $66-85$ & $71-90$ & 76-98 \\
\hline 145 & - & + & - & - & - & - & - & - & - & - & - & - & - & - & - & - \\
\hline 168 & - & + & - & - & - & - & - & - & - & - & - & - & - & - & - & - \\
\hline 182 & - & + & - & - & - & - & - & - & - & - & - & - & - & - & - & - \\
\hline 1046 & + & + & - & - & - & - & - & - & - & - & - & - & - & - & - & - \\
\hline 8 & - & - & - & - & - & - & 0.172 & - & - & - & - & - & - & - & - & - \\
\hline 12 & - & - & - & - & - & - & - & - & - & - & - & - & - & - & - & 0.476 \\
\hline 148 & - & - & 0.192 & - & - & - & - & - & - & - & - & - & - & - & - & - \\
\hline 151 & - & - & 0.120 & - & - & 0.250 & - & - & - & - & - & - & - & - & - & - \\
\hline 184 & - & - & - & - & - & - & - & - & - & - & - & - & - & 0.777 & - & - \\
\hline 1013 & - & - & - & - & - & - & - & - & - & - & - & - & - & 0.159 & - & - \\
\hline 1018 & - & - & - & - & - & - & - & - & - & - & - & 0.267 & - & 0.187 & - & - \\
\hline 1026 & - & - & - & - & - & - & - & - & - & - & - & - & - & 0.176 & - & 0.243 \\
\hline 1036 & - & - & - & - & - & - & - & - & - & - & - & - & - & - & - & - \\
\hline 1105 & - & - & - & - & - & - & - & - & - & - & - & - & - & - & - & - \\
\hline 1133 & - & - & - & 0.486 & - & - & - & - & - & - & - & - & - & - & - & - \\
\hline 1143 & - & - & - & - & 0.560 & - & - & - & - & - & - & - & - & - & - & - \\
\hline
\end{tabular}

Tabla 6

COMPARACION DE LAS REACTIVIDADES EN ELISA, INMUNOTRANSFERENCIA E INMUNODOT EN EL GRUPO CONTROL.

\begin{tabular}{|c|c|c|c|c|c|c|c|c|c|c|c|c|c|c|c|c|}
\hline \multirow[t]{2}{*}{ SUERO } & \multirow[t]{2}{*}{ I.T. } & \multirow[t]{2}{*}{ I.D. } & \multicolumn{14}{|c|}{ ELISA } \\
\hline & & & $1-20$ & $6-25$ & $16-35$ & $26-45$ & $31-50$ & $36-55$ & $41-60$ & $46-55$ & $51-76$ & $56-76$ & $61-80$ & $66-85$ & $71-90$ & 76-98 \\
\hline 214 & - & - & - & - & - & - & - & - & 0.338 & - & 0.129 & - & - & - & - & - \\
\hline 215 & - & - & - & - & - & - & - & - & - & 0.280 & - & - & - & - & - & - \\
\hline 182 & - & - & - & - & - & - & - & - & 0.197 & - & - & - & - & - & - & - \\
\hline 216 & - & - & - & - & - & - & 0.234 & - & - & - & - & - & - & - & - & - \\
\hline 234 & - & - & - & - & - & - & - & - & - & - & - & - & - & - & - & - \\
\hline 239 & - & - & - & - & - & - & - & - & - & - & - & - & - & - & - & - \\
\hline 249 & - & - & - & - & - & - & - & - & - & - & - & - & - & - & - & - \\
\hline 257 & - & - & - & - & 0.499 & - & - & - & - & - & - & - & - & - & - & - \\
\hline 259 & - & - & - & 0.263 & - & - & - & - & - & - & - & - & - & - & - & - \\
\hline
\end{tabular}




\section{Discusión}

El propósito de esta investigación fue definir las regiones de la proteína E7 de VPH16 que son reconocidas por pacientes con CA INV, NIC y controles normales. Con este fin, se analizaron 249 sueros mediante el ensayo de ELISA empleando 14 péptidos sintéticos sobrelapados de 20 aminoácidos de longitud. Los principales hallazgos fueron:

- Las regiones de la proteína E7 de VPH16 reconocidas por los pacientes con CA INV fueron aquellas representadas por los péptidos E7 (1-20) y E7 (66-85). La presencia de anticuerpos hacia esos péptidos mostró una asociación significativa con carcinoma cervical.

- Las reactividades del grupo CA INV contra los péptidos sintéticos E7 (1-20) y E7 (66-85) fueron confirmadas por inmunotransferencia con E7-VPH16 recombinante.

- No se observaron diferencias significativas en la prevalencia de anticuerpos anti-E7 entre mujeres con NIC y controles.

- De acuerdo con los resultados obtenidos en inmunotransferencia con la proteína E7-VPH16 recombinante, las reactividades de pacientes y controles hacia péptidos sintéticos diferentes de E7 (1-20) ó E7 (66-85) son muy probablemente inespecíficas.

Se ha reportado la existencia de epítopes en E7 de VPH16 tanto en la región E7 (1-20) como en la región E7 (66-85), identificadas en este trabajo, siendo E7 (1-20) la más frecuentemente encontrada.

Parte o toda la región E7 (1-20) está contenida en los péptidos E7:1 (aa 1-20) reportada por Krchnak et al., (1990); E7:1 reportada por Dillner, (1990) y E701 (aa 635) reportada por Müller et al., (1992).

En este último trabajo Müller encuentra anticuerpos hacia el péptido E7 (6-35) en un 37\% de pacientes con carcinoma cervical positivo para ADN de VPH16 versus un $9 \%$ en controles, en nuestro estudio, encontramos menos prevalencia de anticuerpos en pacientes con Ca cervical (11\%). Sin embargo, es de resaltar que incluimos toda clase de pacientes sin tomar en cuenta el diagnóstico viral. Encontramos una muy baja reactividad en pacientes con NIC y ninguna reactividad en controles. Esta última diferencia puede ser debida a la existencia de epítopes no específicas entre los aminoácidos 21 a 35, reconocidas por pacientes y controles en el estudio de Müller.

Es claro que las reactividades encontradas en éste y otros estudios no son fáciles de comparar, debido en parte al hecho de que los péptidos no son exactamente iguales. Quisiéramos recalcar que en la región carboxy terminal de E7 (66-85), encontramos una epítope altamente reactiva en el grupo de CA INV, con una asociación significativa con la enfermedad, puesto que no fue reconocida por individuos normales. Estos resultados concuerdan con lo reportado por Dillner et al., (1994).

Con el propósito de verificar si las reactividades antipéptido observadas fueron inducidas por una exposición previa a la proteína E7 silvestre, comparamos esas reactividades con aquellas obtenidas con la proteína E7 recombinante. La inmunotransferencia confirmó los ca- sos positivos en ELISA del grupo de CA INV pero no de los controles. Además, detectó casos positivos adicionales en los grupos CA INV y NIC pero no en el grupo control. La diferencia entre los grupos CA INV y control fue más pronunciada ( $28.8 \%$ v.s $0 \%$ ) comparada con la obtenida en ELISA con E7 (1-20), E7 (66-85) o ambos. La mayor sensibilidad de la técnica de inmunotransferencia, comparada con la técnica de ELISA para discriminar entre los grupos de CA INV y controles puede deberse a la presencia de epítopes lineales adicionales en la proteína recombinante usada en este ensayo, es probable que esas epítopes adicionales no estén representadas en el set de péptidos empleado, o que la conformación adoptada por los péptidos en el soporte sólido no sea reconocida por los anticuerpos. Otra posibilidad sería que el sistema empleado para calcular los puntos de corte haya generado valores subóptimos.

La alta especificidad de nuestro ensayo de inmunotransferencia está en concordancia con varios estudios previos (Jochmus-Kudielka et al., 1989; Kanda et al., 1992; Müller et al., 1992). En un trabajo en curso, (Mesa M \& Orozco O, resultados no publicados) usando sueros de 30 pacientes con CA cervical invasivo y de 30 controles sanos, encontramos este mismo nivel de especificidad y sensibilidad en la inmunotransferencia. Sin embargo, existen reportes de una baja especificidad (Jenison et al., 1990). Como con los péptidos sintéticos, este desacuerdo puede deberse a diferencias en los antígenos empleados en los ensayos.

Las reactividades hacia péptidos sintéticos diferentes de E7 (1-20) ó (66-85), que se presentaron en los tres grupos de estudio, no fueron confirmadas por inmunotransferencia. Estos péptidos probablemente adoptan conformaciones en el soporte sólido que inducen respuestas de reacción cruzada con otras proteínas; la probabilidad de que la reactividad observada haya sido inducida por E7 es muy baja, ésta puede ser inespecífica. Estos péptidos también pueden representar partes internas de la proteína E7 que muestran reacción cruzada con proteínas no relacionadas.

La técnica de inmunotransferencia fue más sensible que el inmunodot para discriminar entre mujeres con CA INV y controles. Esto se debe probablemente a diferencias en el tratamiento del antígeno. En el grupo de NIC, el inmunodot fue más sensible que la inmunotransferencia y la ELISA, tal vez debido a que los pacientes en el grupo de NIC tienen anticuerpos contra epítopes conformacionales parcialmente renaturadas luego de la diálisis del antígeno.

En resumen, este trabajo ha dado soporte adicional a la asociación de la respuesta de anticuerpos contra epítopes de E7 de VPH16 con neoplasia cervical. La reactividad hacia los péptidos 1-20 y 66-85 fue altamente específica. Ninguno de los controles reconoció estos antígenos. Sería importante probar estos sueros con proteínas E7 de otros tipos virales para determinar la utilidad de los anticuerpos anti E7 de VPH16 como marcadores de enfermedad o indicadores de inmunogenicidad de las proteínas de VPH luego de la infección viral. La no 
reactividad de estos sueros hacia péptidos sobrelapados de E7 de VPH18 (Bravo, M; Orozco O; resultados no publicados) apoyan la primera hipótesis.

\section{Agradecimientos}

Este estudio fue financiado en parte por COLCIENCIAS. Los autores desean expresar sus agradeci- mientos al Dr. John Jairo Aponte, por su colaboración en el análisis estadístico; a los Dres. Keerti Shah y Mario Posada, por la revisión de este manuscrito; al Instituto de Inmunología por la provisión de péptidos sintéticos; a la Liga Colombiana de Lucha contra el Cáncer, Seccional Bogotá, por habernos permitido la obtención de las muestras del grupo control.

\section{BIBLIOGRAFIA}

1. Berthold H. Plasmid pGEX-5t: An alternative system for expression and purification of recombinant proteins. Biotechnology letters. 1992; 14: $245-250$.

2. Dillner J. Mapping of linear epitopes of Human Papillomavirus type 16. The E1, E4, E5, E6 and E7 open reading frames. Int. J. Cancer. 1990; 46: 703-711.

3. Dillner J. Antibody responses to defined HPV epitopes in cervical neoplasia. Papillomavirus report. 1994; 5: 35-41.

4. Dürst M., Gissmann L., Ikenberg H. \& Zur Hausen H. A papillomavirus DNA from a cervical carcinoma and its prevalence in cancer biopsy samples form different geographics regions. Proc. Natl. Acad. Sci. USA. 1983; 80: 3812-3815.

5. Dyson N., Howley PM., Muneger K. \& Harlow E. The human papillomavirus $16 \mathrm{E} 7$ oncoprotein is able to bind to the retinoblastoma gene product. Science. 1989; 243: 934-937.

6. Galloway DA \& MC Dougalls JK. Human Papillomavirus and Carcinomas. Adv. in Virus Res. 1989; 37: 125-171.

7. Houghten R. General method for the rapid solid phase synthesis of large numbers of peptides: Specificity of antigen-antibody interaction at the level of individual amino acids. Proc. Natl. Acad. Sci. USA 1985; 82: 5131-5135.

8. Jenison SA., Yu X., Valentine JM., Koutsky LA., Christiansen AE., Beckman AM \& Galloway DA. Evidence of prevalent genital-type human papillomavirus infections in adults and children. J. Infect. Dis. 1990; 162: 69.

9. Jochmus-Kudielka I., Schneider A., Braun R., Kimmig R., Koldovsky U., Schneweis KE., Seedorf K \& Gissmann L. Antibodies against the human papillomavirus type 16early proteins in human sera: correlation of anti-E7 reactivity with cervical cancer. JNCI. 1989; 81: 1698 1704.

10. Kanda T., Onda T., Zanma S., Yasugi T., Furuno A., Watanabe S., Kawana T., Sugase M., Ueda K., Sonada T., Suzuki S., Yamashiro T., Yoshikawa H., Yoshiike K. Independent association of antibodies against human papillomavirus type $16 \mathrm{E} 1 / \mathrm{E} 4$ and $\mathrm{E} 7$ proteins with cervical cancer. 1992

11. Krchnak V., Vagner J., Suchankova A., Krcmar M., Ritterowa L \& Vonka V. Synthetic peptides derived from E7 region of human papillomavirus type 16 used as antigens in ELISA. J. Gen. Virol. 1990; 71: 2719-2724.

12. Müller M., Viscidi R., Sun Y., Guerrero E., Hill P., Shah F., Bosch X., Muñoz N., Gissmann L \& Shah K. Antibodies to E6 and E7 proteins as markers for HPV-16 associated invasive cervical cancer. Virology, 1992; 187: 508-514.

13. Pfister H. Human papillomavirus and genital cancer. Adv. in Cancer Res. 1987; 48: 113-147.

14. Phelps W., Yee L., Munger K \& Howley P. The Human papillomavirus type 16 E7 encodes transactivation and transformation functions similar to those of adenovirus EIA. Cell. 1988; 53: 539-547.

15. Sambrook J., Fritsch EF \& Maniatis T. "Molecular Cloning: A Laboratory Manual", 2nd edition. New York: Cold Spring Harbor Laboratory. 1989.

16. Seedorf K., Ottersdorf T., Krammer G \& Rowekamp WG. Identification of early proteins of the papillomavirus type 16 (HPV 16), and type 18 (HPV 18) in cervical carcinoma cells. EMBO. J. 1987; 139-144.

17. Tindle RW \& Frazer IH. Immune response to Human Papillomaviruses. Curr. topics Microbiol. Immunol. 1994; 186: 217-251. 